\title{
Increased cortisol metabolism in women with pregnancy-related hypertension
}

\author{
Katarzyna Kosicka $\mathbb{1}^{1} \cdot$ Anna Siemiątkowska (i] ${ }^{1} \cdot$ Agata Szpera-Goździewicz $\mathbb{D}^{2} \cdot$ Mariola Krzyścin ${ }^{2} \cdot$ \\ Grzegorz H. Bręborowicz ${ }^{2}$. Franciszek K. Główka $\mathbb{1}^{1}$
}

Received: 5 December 2017 / Accepted: 17 March 2018 / Published online: 2 April 2018

(c) The Author(s) 2018

\begin{abstract}
Purpose The diminished function of $11 \beta$-hydroxysteroid dehydrogenase $2(11 \beta$-HSD2) was found in placentae from preeclamptic pregnancies. Here, we examine the overall maternal glucocorticoid balance in pregnancy-related hypertension. We

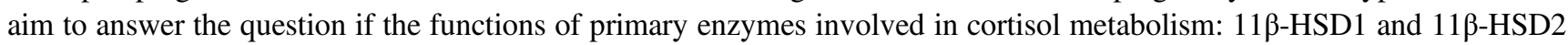
and 5-reductases (both $5 \alpha$ - and $5 \beta$ ) are altered in the course of hypertensive pregnancy.

Methods We determined plasma and urinary cortisol and cortisone as well as their urinary tetrahydro- and allo-tetrahydrometabolites, both in free and conjugated forms in samples obtained from 181 Polish women in the third trimester of pregnancy. We compared steroid profiles in women with preeclampsia (PE), gestational hypertension $(\mathrm{GH})$, chronic hypertension $(\mathrm{CH})$ and in normotensives (controls).

Results We found significant differences in glucocorticoid balance in pregnancy-related hypertension. Plasma cortisol to cortisone was significantly lower in PE than in controls (3.00 vs. $4.79 ; p<0.001)$. Increased function of renal $11 \beta$-HSD2 in $\mathrm{PE}$ and GH was manifested by significantly lower urinary free cortisol to cortisone ratio $(0.169$ and 0.206 vs. 0.277 in controls; $p<0.005)$. Markedly enhanced metabolism of cortisol was observed in pregnancy-related hypertension, with no significant alterations in $\mathrm{CH}$, and the changes were more clearly expressed in PE than in $\mathrm{GH}$.

Conclusions The glucocorticoid balance in PE and GH is shifted towards decreasing cortisol concentration either due to intensified conversion to cortisone or enhanced production of tetrahydro and allo-tetrahydrometabolites.
\end{abstract}

Keywords Cortisol $\cdot$ Tetrahydrometabolites $\cdot 11 \beta$-hydroxysteroid dehydrogenase $\cdot 5 \beta$-reductase

\section{Introduction}

Pathogenesis of preeclampsia (PE) is not fully explained. It is believed to be initiated by the placental ischemia. In PE, the invasion of the trophoblast is aberrant; the spiral arteries remodeling is impaired. Therefore they are narrowed and

Electronic supplementary material The online version of this article (https://doi.org/10.1007/s12020-018-1586-4) contains supplementary material, which is available to authorized users.

Katarzyna Kosicka

kasiakosicka@ump.edu.pl

1 Department of Physical Pharmacy and Pharmacokinetics, Poznan University of Medical Sciences, 6 Święcickiego Street, Poznań 60781, Poland

2 Department of Perinatology and Gynecology, Poznan University of Medical Sciences, 33 Polna Street, Poznań 60-535, Poland resistive. Placental hypoperfusion generates oxidative as well as endoplasmic reticulum stress, and the release of antiangiogenic factors into the circulation (soluble fms-like tyrosine kinase - sFlt-1, and soluble endoglin - sEng) [1, 2]. The imbalance between pro and antiangiogenic factors leads to endothelial dysfunction [1,3]. Oxidative stress also induces the release of proinflammatory cytokines and chemokines [2]. The systemic endothelial dysfunction, occurring in PE, is manifested in glomerular endotheliosis and proteinuria, hypertension, as well as coagulation abnormalities [3].

A healthy pregnancy is a state of hyperactivity of HPA axis and of hypercortisolism [4, 5]. Elevated cortisol (F) levels can be partially attributed to the estrogen-stimulated increase of corticosteroid-binding globulin (CBG). In normal pregnancy CBG levels rise with advancing gestation, with a corresponding increase of total plasma $\mathrm{F}$, with a decline from 36 weeks onwards; this decline results in the rise of free $\mathrm{F}$ in maternal plasma [5]. On the other hand, the 
placenta is an important source of $\mathrm{CRH}$, which further stimulates the release of maternal ACTH. It leads to the elevation of $\mathrm{F}$ levels in the course of pregnancy $[4,5]$. $\mathrm{F}$ influences the hypothalamic CRH in a negative feedback loop, while the placental $\mathrm{CRH}$ is strongly stimulated by $\mathrm{F}$ in a mechanism of positive feedback loop [5]. During normal labor, maternal $\mathrm{CRH}, \mathrm{ACTH}$ and $\mathrm{F}$ levels increase in maternal plasma and then drop at 4 days postpartum [4].

Lately, more and more is discussed the improper metabolism of glucocorticoids (GCs) in pregnancies with adverse outcomes $[6,7] . \mathrm{F}$ is metabolized mainly by the $11 \beta$-hydroxysteroid dehydrogenase (11 $\beta$-HSD), of which two isoforms (type 1 and type 2 ) have been described. $11 \beta$ HSD2 inactivates $F$ to cortisone (E) and is localized mainly in the kidneys and the placenta, while $11 \beta$-HSD1 regenerates $\mathrm{E}$ to $\mathrm{F}$ in the liver and the fat tissue. Both $\mathrm{F}$ and $\mathrm{E}$ are then catabolized by $5 \alpha$ - and $5 \beta$-reductase in the liver and converted into tetrahydro- and allo-tetrahydrometabolites $[8,9]$.The disturbed activity of placental $11 \beta$-HSD2 in the course of PE was emphasized in last years [6]. It has not been yet discovered whether the abnormal function of $11 \beta$ HSD2 occurs in PE only locally (in the placenta) or it affects the whole body of a pregnant patient. Most research groups focus solely on the placental $11 \beta$-HSD2 as the enzyme localized in the tissue, which directly influences the proper development of the fetus [7]. Few available studies concerning the function of non-placental $11 \beta-H S D 2$ in GH and PE are still inconclusive [10-12].

There are limited data reporting levels of $\mathrm{F}$ and $\mathrm{E}$ metabolites in pregnant women [13-15], some of which refers to spot urine only [14]. Others include women in the first weeks of pregnancy [15] or-like the study from 1980 - concern only the tetrahydrometabolites of $\mathrm{F}$ and $\mathrm{E}$ assessed in samples from 6 patients [16]. To our best knowledge, the only analysis of the function of $11 \beta$-HSD1 in $\mathrm{GH}$ and PE was published more than 20 years ago and comprised small study population [10]. However, the recent data showed that some polymorphisms in HSDI1B1 gene, encoding $11 \beta$-HSD1, are linked to higher risk of developing PE [17]. Moreover, some authors revealed the increased levels of $11 \beta$-HSD1 in decidua of PE women [18]. These facts show the need for further research in the field of $11 \beta$ HSD function in pregnancy.

The aim of this study was to evaluate the overall maternal GC balance in pregnancy-related hypertension (both GH and PE) and to verify if the functions of primary

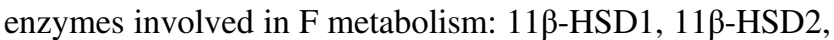
$5 \alpha$ and $5 \beta$-reductase are altered in hypertensive pregnancy. Plasma and urinary F and $\mathrm{E}$, as well as their metabolites in urine, were determined and served as a basis for further indirect assessment of enzymes functions. The research question was whether the $\mathrm{F}$ conversion is impaired in the body of women suffering from GH and/or PE.

\section{Materials and methods}

\section{Study participants}

The study included 181 Polish women in the third trimester of pregnancy (at least 27th week of gestation, WG), recruited between 2013 and 2016 from inpatients of the Gynecological and Obstetric Clinical Hospital as well as healthy volunteers attending antenatal classes in Poznan.

The pregnant women were divided into four groups (Table 1). The hypertensive population comprised patients with chronic hypertension $(\mathrm{CH})$ and pregnancy-related hypertension divided into GH and PE. $\mathrm{CH}$ patients were included as a separate group to verify if the observed changes are specific for pregnancy, and not due to hypertension per se. The normotensive $(<140 / 90 \mathrm{~mm} \mathrm{Hg}$, according to WHO [19]) pregnant women served as a control group. $\mathrm{CH}$ was diagnosed in women who suffered from hypertension before pregnancy or who developed it before 20th WG. GH was diagnosed in pre-pregnancy normotensive women with de novo hypertension after 20th WG, without significant proteinuria. PE was diagnosed in patients with hypertension (pre-existing or developing in pregnancy) and the new onset of substantial proteinuria after 20th WG (protein excretion $>0.3 \mathrm{~g} / 24 \mathrm{~h}$ ) [20]. The hypertensive patients were treated with the antihypertensive drugs that are recommended to use during pregnancy. The hypothyroid patients were treated with levothyroxine; two asthmatic women were taking inhaled GCs (budesonide).

Pre-pregnancy BMI was based on the maternal selfreport at the enrollment. Prematurity was recognized when delivery occurred before 37 WG. Small for gestational age (SGA) babies were defined as those whose birth weight was below the 10th percentile for gestational age (GA) and gender, according to data for Wielkopolska region [21]. Giving birth to the SGA child was an exclusion criterion for controls. The exclusion criteria for the whole study population were: multiple pregnancy, pre-pregnancy diabetes, other than hypothyroidism endocrine diseases, mental and liver disorders (including cholestasis which was associated with reduced placental 11 $\beta$-HSD2 expression [22]), infectious diseases, and stillbirth.

The study protocol was in accordance with the Helsinki Declaration and written informed consent was received from each participant. Ethical Committee at Poznan University of Medical Sciences approved the protocol.

\section{Determination of steroids in plasma and urine}

Each woman was required to provide one urine sample from the 24h-urine collection and one morning blood sample as described in detail previously [12]. Finally, plasma samples 
Table 1 Characteristics of the patients

\begin{tabular}{|c|c|c|c|c|}
\hline Characteristics* & $\begin{array}{l}\text { Controls } \\
(n=63)\end{array}$ & $\begin{array}{l}\mathrm{PE} \\
(n=42)\end{array}$ & $\begin{array}{l}\mathrm{GH} \\
(n=47)\end{array}$ & $\begin{array}{l}\mathrm{CH} \\
(n=29)\end{array}$ \\
\hline Age $(y)^{\mathrm{a}}$ & $30.4 \pm 4.7$ & $32.0 \pm 5.1$ & $30.2 \pm 4.3$ & $31.3 \pm 6.8$ \\
\hline - Age $\geq 35^{\mathrm{b}}$ & $11(17.5 \%)$ & $13(31.0 \%)$ & $7(14.9 \%)$ & $9(31.0 \%)$ \\
\hline BMI before pregnancy $\left(\mathrm{kg} / \mathrm{m}^{2}\right)^{\mathrm{c}}$ & $21.4(19.6-23.8)$ & $24.1(21.7-26.0)^{2}$ & $25.0(22.6-29.4)^{3}$ & $25.2(20.6-32.0)^{1}$ \\
\hline$\cdot \mathrm{BMI} \leq 18.5^{\mathrm{b}}$ & $6(9.5 \%)$ & $1(2.5 \%)$ & $0(0.0 \%)^{1}$ & $3(10.3 \%)$ \\
\hline - $\mathrm{BMI} \geq 25^{\mathrm{b}}$ & $12(19.0 \%)$ & $13(32.5 \%)$ & $23(50.0 \%)^{3}$ & $15(51.7 \%)^{2}$ \\
\hline GA at sample collection $(\mathrm{wks})^{\mathrm{c}}$ & $37(33-39)$ & $34(31-37)^{1}$ & $37(34-38)$ & $35(32-37)$ \\
\hline \multicolumn{5}{|l|}{ Labour information } \\
\hline - Nulliparity ${ }^{\mathrm{b}}$ & $26(41.3 \%)$ & $28(66.7 \%)^{1}$ & $25(53.2 \%)$ & $17(58.6 \%)$ \\
\hline - GA at delivery $(w k s)^{b}$ & $39(38-40)$ & $36(33-38)^{3}$ & $39(37-39)$ & $39(38-39)$ \\
\hline - Prematurity $^{\mathrm{b}}$ & $4(6.8 \%)$ & $22(55.0 \%)^{3}$ & $6(12.8 \%)$ & $2(7.1 \%)$ \\
\hline - Caesarean section ${ }^{\mathrm{b}}$ & $35(59.3 \%)$ & $31(81.6 \%)$ & $26(57.8 \%)$ & $19(73.1 \%)$ \\
\hline - Infant birth weight $(\mathrm{g})^{\mathrm{c}}$ & $3490(3100-3800)$ & $2030(1465-3020)^{3}$ & $3120(2680-3600)^{1}$ & $3430(2940-3720)$ \\
\hline - $\mathrm{SGA}^{\mathrm{b}}$ & $0(0.0 \%)$ & $19(48.7 \%)^{3}$ & $12(25.5 \%)^{3}$ & $5(18.5 \%)^{2}$ \\
\hline - Female fetus ${ }^{\mathrm{b}}$ & $23(39.0 \%)$ & $19(48.7 \%)$ & $24(51.1 \%)$ & $13(46.4 \%)$ \\
\hline \multicolumn{5}{|l|}{ Medical history } \\
\hline - Hypothyroidism ${ }^{\mathrm{b}}$ & $7(11.1 \%)$ & $7(16.7 \%)$ & $10(21.3 \%)$ & $3(10.3 \%)$ \\
\hline - Gestational diabetes ${ }^{\mathrm{b}}$ & $5(7.9 \%)$ & $6(14.3 \%)$ & $6(12.8 \%)$ & $5(17.2 \%)$ \\
\hline - Asthma ${ }^{\mathrm{b}}$ & $0(0.0 \%)$ & $1(2.4 \%)$ & $3(6.4 \%)$ & $2(6.9 \%)$ \\
\hline \multicolumn{5}{|l|}{ Medical therapy } \\
\hline - Methyldopa ${ }^{b}$ & $0(0.0 \%)$ & $38(95.0 \%)^{3}$ & $41(100.0 \%)^{3}$ & $25(86.2 \%)^{3}$ \\
\hline - Metoprolol ${ }^{\mathrm{b}}$ & $2(3.3 \%)$ & $6(15.0 \%)^{1}$ & $3(6.4 \%)$ & $4(13.8 \%)$ \\
\hline - Nitrendypine ${ }^{b}$ & $1(1.6 \%)$ & $20(50.0 \%)^{3}$ & $4(8.5 \%)$ & $6(20.7 \%)^{2}$ \\
\hline - verapamil ${ }^{\text {b }}$ & $6(9.8 \%)$ & $3(7.3 \%)$ & $6(12.8 \%)$ & $2(6.9 \%)$ \\
\hline - Magnesium sulfate ${ }^{b}$ & $0(0.0 \%)$ & $11(27.5 \%)^{3}$ & $2(4.3)$ & $0(0.0 \%)$ \\
\hline
\end{tabular}

$P E$ pre-eclampsia, $G H$ gestational hypertension, $\mathrm{CH}$ chronic hypertension

*cases with missing information are excluded

${ }^{1} p<0.05 ;{ }^{2} p<0.005 ;{ }^{3} p<0.01$

${ }^{\mathrm{a}}$ values presented as mean $\pm \mathrm{SD}$

${ }^{\mathrm{b}}$ values given as $n(\%)$

${ }^{c}$ values shown as median (interquartile range)

were obtained from 170 while urine samples from 177 participants.

Total plasma $\mathrm{F}$ and $\mathrm{E}$ were determined by a validated HPLC-FLD method [12]. The amounts of urinary free and total steroids were assessed applying a validated HPLC-MS/ MS method [23]. Six urinary GCs were determined: F, E, and their metabolites (tetrahydrocortisol, THF; tetrahydrocortisone, THE; allo-tetrahydrocortisol, alloTHF; allotetrahydrocortisone, alloTHE). Urinary free $\mathrm{F}$ and $\mathrm{E}$ were described as UFF and UFE, while free metabolites of $\mathrm{F}$ and $\mathrm{E}$ as $\mathrm{THF}_{\text {free }}, \mathrm{THE}_{\text {free, }}$, alloTHF free, alloTHE $\mathrm{Trree}_{\text {f }}$ The total urinary steroids, obtained after hydrolysis with Helix pomatia, were marked with the subscript "tot": $F_{\text {tot }}, E_{\text {tot }}$, $\mathrm{THF}_{\text {tot }}, \mathrm{THE}_{\text {tot }}$, alloTHF ${ }_{\text {tot }}$, alloTHE $\mathrm{THo}_{\text {tot }}$ The amounts of steroids excreted per day were evaluated based on the 24-h urine volume and were expressed as $\mu \mathrm{g}$ of steroid compound per mmol of urinary creatinine $(\mathrm{Cr})$. Each time when the sum of THF and alloTHF was used in calculations they were described as "THFs", and consequently the sum of THE and alloTHE—as "THEs".

\section{Parameters reflecting the GC balance}

The functions of $11 \beta-\mathrm{HSD}, 5 \alpha$ and $5 \beta$-reductase were thoroughly estimated using the recognized parameters $[8,9$, 24-28]. In contrast to other authors who do not consider alloTHE, we used both THE and alloTHE for accurate calculations, similarly to THF and alloTHF. As in the published literature there is no consistency which forms of compounds (free $[8,27]$ or total $[9,28]$ ) should be used in most ratios, we calculated the ratios twice (using unconjugated and conjugated steroids) to compare the results. 
The following parameters were defined:

1. for 11 $\beta$-HSD2-UFF/UFE, considered as the best predictor of the function of $11 \beta$-HSD2

2. for $11 \beta-\mathrm{HSD} 1-$ the $\mathrm{F}$ and $\mathrm{E}$ metabolites ratios: $\mathrm{THFs}_{\text {tot }} / \mathrm{THEs}_{\text {tot }}$ and $\mathrm{THFs}_{\text {free }} / \mathrm{THEs}_{\text {free, providing an }}$ index of global 11 $\beta$-HSD activity; elevated values of the ratios (with the normal UFF/UFE values) suggest an abnormal function of $11 \beta-H S D 1$

3. for $5 \alpha / \beta$-reductase-alloTHF tot $/ \mathrm{F}_{\text {tot }}$ and $\mathrm{THF}_{\text {tot }} / \mathrm{F}_{\text {tot }}$ reflecting the activity of $5 \alpha$ and $5 \beta$-reductase, respectively; alloTHF tot $/ \mathrm{THF}_{\text {tot }}$, assessing the overall balance between $5 \alpha$ and $5 \beta$-reductase and indicating which pathway of $\mathrm{F}$ metabolism dominates: the reduction to alloTHF or to $\mathrm{THF}$

4. for net glucocorticoid balance in the body: plasma $\mathrm{F} /$ $\mathrm{E}$; urinary $\mathrm{F}_{\text {tot }} / \mathrm{E}_{\text {tot }}$; $\mathrm{THFs}_{\mathrm{tot}} / \mathrm{UFF}$, which shows the irreversible conversion of $\mathrm{F}$ to its metabolites. $\left(\mathrm{THFs}_{\text {tot }}+\mathrm{THEs}_{\mathrm{tot}}\right) / \mathrm{UFF}$ represents a non-invasive measure of the metabolic clearance of $\mathrm{F}$. $\left(\mathrm{THFs}_{\mathrm{tot}}+\right.$ $\left.\mathrm{THEs}_{\text {tot }}\right) /(\mathrm{UFF}+\mathrm{UFE})$ represents a more complex index of total $11 \beta$-HSD activity. The sum of four major urinary GC metabolites $\left(\mathrm{THFs}_{\mathrm{tot}}+\mathrm{THEs}_{\text {tot }}\right.$, normalized for urinary $\mathrm{Cr}$ ) indicates the $\mathrm{GC}$ secretion.

Additionally, the levels of conjugation with glucuronic and sulphuric acid were evaluated for urinary F, E, THF, and THE. Those levels were calculated for each steroid as the ratio of free and total compound excreted per $24 \mathrm{~h}$ and were expressed in percentages $(\%)$.

\section{Statistical analysis}

The study was performed in a case-control structure. The statistical analysis was accomplished using Statistica 12.0 software (StatSoft Inc., Tulsa, OK, USA). In each analysis, a $p$-value of $<0.05$ was considered significant. Prior to analysis, the data were checked for normal distribution with the Shapiro-Wilk test. For continuous variables, the differences between non-parametric data were estimated using the Mann-Whitney $U$ test while in other cases, the analysis of variance (ANOVA test) was applied. The differences in categorical data were tested with Fisher's exact test. The normally distributed data were reported as a mean \pm standard deviation, the non-normally distributed data as medians (interquartile range) and the categorical data as a number of patients (\%). The Spearman test was performed in each group to check for simple correlations between the calculated parameters and GA.

Multiple regression analysis was used to detail the results from Mann-Whitney $U$ test. The results were reported only when the built models were significant ( $p$-value was $<0.05$ ). In all analyses based on multiple regression, the cases with residuals (the differences between the observations and the estimated values) greater than three standard deviations were not included in the analysis.

\section{Results}

\section{Plasma and urinary steroids}

The plasma and urinary GCs levels observed in the study groups (Mann-Whitney $U$ test) are presented in Supplementary Table 1.

\section{Results below the lower limit of quantification (LLOQ) or the limit of detection (LOD)}

During analyses, a few patients (mostly from PE group) presented results of free steroids $<$ LLOQ or even $<$ LOD. In one case (GH group) the level of alloTHF $\mathrm{TH}_{\text {tot }}$ was $<$ LOD. Evidently, the results < LLOQ are measured with lower precision and accuracy and the values $<$ LOD are impossible to estimate. They are, however, still a valuable source of information. Therefore, omitting them in further calculations could overestimate the results obtained by the study group and even lead to the false conclusions [29]. Considering above, we decided not to exclude the patients with results $<$ LLOQ or $<$ LOD from the statistics. We applied the following approaches to minimize the potential error:

- All detectable concentrations were analyzed statistically (also the results between LLOQ and LOD), as shown previously by others in pharmacokinetics studies [29]. The method was applied to plasma $\mathrm{E}$ in four patients. The results $<$ LLOQ were also obtained for urinary alloTHF free and alloTHE free in $>97 \%$ of samples. Therefore, obviously, the results for alloTHF free and

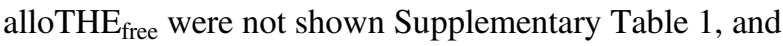
they were excluded from the further analyses. The $\mathrm{THFs}_{\text {free }}$ and $\mathrm{THEs}_{\text {free }}$ were, therefore, equal to $\mathrm{THF}_{\text {free }}$ and $\mathrm{THE}_{\text {free, }}$, respectively.

- For undetectable steroids (the results < LOD), the concentrations were calculated by dividing the LOD by the square root of 2, as recommended in the literature for studies when relatively few data are <LOD [30]. This approach is used in clinical studies considering patients with enzyme deficiency [31]. The method was applied to replace the missing data for UFF in four patients, $\mathrm{THF}_{\text {free }}$ in four patients and alloTHF tot in one patient. The censored concentrations for UFF were replaced by $0.28 \mathrm{ng} / \mathrm{mL}$ $(\mathrm{LOD}=0.4 \mathrm{ng} / \mathrm{mL})$, while for $\mathrm{THF}_{\text {free }}$ and alloTHF tot with $0.7 \mathrm{ng} / \mathrm{mL}(\mathrm{LOD}=1.0 \mathrm{ng} / \mathrm{mL})$. Such obtained results were then multiplied by the urine volume (and normalized for $\mathrm{Cr}$ level when necessary) and used for further calculations. 


\section{Results higher than the ULOQ}

The $\mathrm{THE}_{\text {tot }}$ concentrations for 8 patients were $>\mathrm{ULOQ}$ $(5000 \mathrm{ng} / \mathrm{mL}$ in the matrix). For those patients, the urine sample was diluted and re-assessed (the dilution integrity was estimated during method validation [23]).

\section{Parameters reflecting the GC balance}

The values of parameters indicating GC secretion and assessing the function of $11 \beta$-HSD2, $11 \beta$-HSD1, $5 \alpha$, and $5 \beta$-reductase, as well as the overall balance between those enzymes, are presented in Table 2 . The table also contains the results from Mann-Whitney $U$ test.

Multiple regression analysis was applied to particularize the Mann-Whitney $U$ test. The PE group was characterized by significantly earlier GA at sample collection as compared to controls. Therefore, GA at sample collection was considered as an unintended confounder, and the models containing each parameter (as the dependent variable), PE and GA at sampling (as independent variables) were built. The results (Supplementary Table 2) confirmed that the dependences observed in Mann-Whitney $U$ test are the consequence of the disease and not the earlier sampling time.

Furthermore, the stepwise forward multiple regression was performed (selection $F=1$, elimination $F=0$ ). The dependent variables in such models were the parameters calculated from endogenous GC levels. The independent variables included in all models were: a hypertensive disorder of pregnancy (respectively $\mathrm{PE}, \mathrm{GH}$ or $\mathrm{CH}$ ) along with the factors that may influence GC equilibrium (maternal age, hypothyroidism, diabetes, baby's gender, nulliparity, GA at sampling and pre-pregnancy BMI). The most important results from the stepwise multiple regression analyses reporting the associations between parameters and particular disease ( $\mathrm{PE}, \mathrm{GH}$ or $\mathrm{CH})$ are presented in Table 3. The details are shown in Supplementary Table 3. Each time, a semi-partial correlation (R) and a p-value were noted.

The stepwise multiple regression revealed that PE significantly influenced most of the analyzed parameters. In most cases, PE was the sole significant predictor of the response variables. The analysis showed that GH was

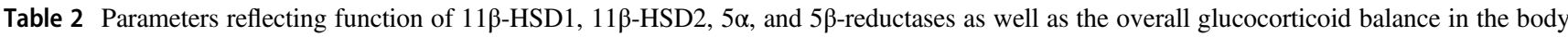

\begin{tabular}{|c|c|c|c|c|}
\hline & Controls & $\mathrm{PE}$ & GH & $\mathrm{CH}$ \\
\hline \multicolumn{5}{|l|}{ Function of $11 \beta-H S D 2$} \\
\hline UFF/UFE & $0.277(0.198-0.373)$ & $0.169^{3}(0.115-0.221)$ & $0.206^{2}(0.158-0.261)$ & $0.282(0.207-0.421)$ \\
\hline \multicolumn{5}{|l|}{ Function of $11 \beta$-HSD1 } \\
\hline $\mathrm{THFs}_{\mathrm{tot}} / \mathrm{THEs}_{\mathrm{tot}}$ & $0.280(0.235-0.337)$ & $0.346^{1}(0.256-0.445)$ & $0.318(0.247-0.373)$ & $0.271(0.228-0.385)$ \\
\hline $\mathrm{THF}_{\text {free }} / \mathrm{THE}_{\text {free }}$ & $0.498(0.353-0.720)$ & $0.416 *(0.268-0.601)$ & $0.476(0.347-0.606)$ & $0.428(0.264-0.597)$ \\
\hline \multicolumn{5}{|l|}{ Function of $5 \alpha$ and $5 \beta$-reductases } \\
\hline alloTHF tot $/ \mathrm{F}_{\text {tot }}$ & $0.0477(0.0248-0.0805)$ & $0.0661(0.0264-0.1354)$ & $0.0489(0.0282-0.0916)$ & $0.0391 *(0.0178-0.0487)$ \\
\hline $\mathrm{THF}_{\text {tot }} / \mathrm{F}_{\text {tot }}$ & $2.20(1.63-3.38)$ & $3.51^{3}(2.15-6.11)$ & $3.22^{2}(2.25-4.59)$ & $3.19 *(1.85-4.48)$ \\
\hline alloTHF $F_{\text {tot }} / \mathrm{THF}_{\text {tot }}$ & $0.0203(0.0133-0.0329)$ & $0.0179(0.0096-0.0249)$ & $0.0151 *(0.0070-0.0330)$ & $0.0106^{2}(0.0074-0.0183)$ \\
\hline \multicolumn{5}{|c|}{ Overall glucocorticoid balance in the body } \\
\hline Plasma F/E & $4.79(3.66-5.76)$ & $3.00^{3}(2.57-4.21)$ & $4.01 *(3.53-5.26)$ & $4.94(3.44-6.07)$ \\
\hline Urinary $\mathrm{F}_{\mathrm{tot}} / \mathrm{E}_{\mathrm{tot}}$ & $1.14(0.86-1.30)$ & $1.08(0.86-1.31)$ & $1.04(0.92-1.26)$ & $1.11(0.89-1.43)$ \\
\hline $\mathrm{THFs}_{\text {tot }}+\mathrm{THEs}_{\text {tot }[\mu \mathrm{g} / \mathrm{mmol} \mathrm{Cr}]}$ & $380.1(292.4-504.5)$ & $394.2(253.8-659.7)$ & $489.7^{1}(346.6-699.3)$ & $450.3(302.8-623.5)$ \\
\hline $\mathrm{THFs}_{\mathrm{tot}} / \mathrm{UFF}$ & $16.80(11.50-25.64)$ & $36.95^{3}(23.04-85.05)$ & $33.07^{3}(18.62-45.22)$ & $23.78 *(13.96-37.59)$ \\
\hline$\left(\mathrm{THFs}_{\mathrm{tot}}+\mathrm{THEs}_{\mathrm{tot}}\right) / \mathrm{UFF}$ & $\begin{array}{l}76.39 \\
(52.28-117.21)\end{array}$ & $140.63^{3}(91.93-322.45)$ & $138.19^{3}(81.07-178.36)$ & $109.81 *(66.52-155.77)$ \\
\hline$\left(\mathrm{THFs}_{\mathrm{tot}}+\mathrm{THEs}_{\mathrm{tot}}\right) /(\mathrm{UFF}+\mathrm{UFE})$ & $15.42(11.39-23.51)$ & $19.47^{1}(13.95-35.80)$ & $23.58^{1}(14.67-33.12)$ & $22.58(12.52-35.30)$ \\
\hline \multicolumn{5}{|c|}{ Steroid conjugation with glucuronides and sulphates } \\
\hline F conjugation degree $[\%]$ & $85.0(81.2-89.5)$ & $90.9^{3}(87.1-94.2)$ & $88.9^{1}(85.2-91.4)$ & $87.1(76.3-91.6)$ \\
\hline E conjugation degree $[\%]$ & $44.2(31.3-53.8)$ & $42.6(33.7-47.9)$ & $42.3(31.2-49.1)$ & $39.0(30.2-52.1)$ \\
\hline THF conjugation degree $[\%]$ & $98.8(98.3-99.0)$ & $99.0^{1}(98.6-99.2)$ & $99.0^{1}(98.6-99.2)$ & $98.8(98.6-99.0)$ \\
\hline THE conjugation degree $[\%]$ & $99.3(99.0-99.5)$ & $99.2(98.8-99.4)$ & $99.3(99.0-99.5)$ & $99.2(98.4-99.4)$ \\
\hline
\end{tabular}

Results are presented as medians (interquartile range) for groups of women with preeclampsia (PE), gestational hypertension (GH), chronic hypertension $(\mathrm{CH})$ and normotensive controls

*close to be significant $(p<0.09)$

${ }^{1} p<0.05 ;{ }^{2} p<0.005 ;{ }^{3} p<0.001$ 
Table 3 Results of the forward multiple regression analyses assessing the relationship between calculated parameters and hypertensive disorder of pregnancy ( $\mathrm{PE}, \mathrm{GH}$ or $\mathrm{CH}$, each in the separate model) after adjustment for factors potentially influencing $\mathrm{F}$ metabolism

\begin{tabular}{|c|c|c|c|}
\hline & $\mathrm{PE}$ & $\mathrm{GH}$ & $\mathrm{CH}$ \\
\hline UFF/UFE & $R=-0.516 ; p<0.001$ & $\mathrm{R}=-0.271 ; p=0.004$ & NS \\
\hline $\mathrm{THFs}_{\text {tot }} / \mathrm{THEs}_{\mathrm{tot}}$ & $R=0.198 ; p=0.045$ & NS & NS \\
\hline $\mathrm{THF}_{\text {free }} / \mathrm{THE}_{\text {free }}$ & $R=-\mathbf{0 . 2 1 4} ; p=\mathbf{0 . 0 3 4}$ & NS & NS \\
\hline alloTHF $\mathrm{tot}_{\text {tot }} / \mathrm{F}_{\text {tot }}$ & $R=0.338 ; p<0.001$ & NS & NS \\
\hline $\mathrm{THF}_{\text {tot }} / \mathrm{F}_{\text {tot }}$ & $R=0.424 ; p<0.001$ & $R=0.233 ; p=0.013$ & NS \\
\hline alloTHF tot $/ \mathrm{THF}_{\text {tot }}$ & NS & NS & $R=-\mathbf{0 . 2 5 2} ; p=\mathbf{0 . 0 2 8}$ \\
\hline plasma F/E & $R=-\mathbf{0 . 4 7 3 ;} p<0.001$ & NS & NS \\
\hline urinary $\mathrm{F}_{\text {tot }} / \mathrm{E}_{\text {tot }}$ & NS & NS & NS \\
\hline $\mathrm{THFs}_{\text {tot }}+\mathrm{THEs}_{\text {tot }}[\mu \mathrm{g} / \mathrm{mmol} \mathrm{Cr}]$ & NS & $R=\mathbf{0 . 2 6 5} ; p=\mathbf{0 . 0 0 7}$ & NS \\
\hline $\mathrm{THFs}_{\text {tot }} / \mathrm{UFF}$ & $R=0.424 ; p<0.001$ & $R=0.430 ; p<0.001$ & NS \\
\hline$\left(\mathrm{THFs}_{\mathrm{tot}}+\mathrm{THEs}_{\mathrm{tot}}\right) / \mathrm{UFF}$ & $R=0.484 ; p<0.001$ & $R=0.342 ; p<0.001$ & NS \\
\hline$\left(\mathrm{THFs}_{\mathrm{tot}}+\mathrm{THEs}_{\mathrm{tot}}\right) /(\mathrm{UFF}+\mathrm{UFE})$ & $R=0.342 ; p<0.001$ & $R=\mathbf{0 . 2 0 6} ; p=\mathbf{0 . 0 2 9}$ & NS \\
\hline F conjugation degree $[\%]$ & $R=0.467 ; p<0.001$ & $R=0.236 ; p=0.010$ & NS \\
\hline E conjugation degree $[\%]$ & NS & NS & NS \\
\hline THF conjugation degree [\%] & $R=\mathbf{0 . 2 4 2} ; p=\mathbf{0 . 0 1 9}$ & $R=\mathbf{0 . 2 4 6} ; p=\mathbf{0 . 0 1 3}$ & NS \\
\hline THE conjugation degree $[\%]$ & $R=-0.233 ; p=0.019$ & NS & NS \\
\hline
\end{tabular}

Each time, a semi-partial correlation $(R)$ and a $p$-value were noted. The associations where the sole predictor of the response variable was the hypertensive disorder of pregnancy are marked in bold

UFF urinary free cortisol, UFE urinary free cortisone, THF tetrahydrocortisol, THE tetrahydrocortisone, alloTHF allo-tetrahydrocortisol, alloTHE allo-tetrahydrocortisone, $N S$ not significant

the single significant predictor of few response variables. The $\mathrm{CH}$ was the sole significant predictor of alloTHF ${ }_{\text {tot }} /$ $\mathrm{THF}_{\text {tot }}$ - the tendency seen in Mann-Whitney $U$ test was confirmed.

\section{Conjugation level of particular steroids}

The degrees of conjugation with glucuronic and sulphuric acid for certain steroids are presented in Table 2. The Spearman tests showed that in normotensive pregnant women, the conjugation degree of $\mathrm{F}$ and $\mathrm{E}$ is increasing with GA $(R=0.485 ; p<0.0001$ for $\mathrm{F}$ and $R$ $=0.264 ; p=0.038$ for E). Such observations were not confirmed in a hypertensive population. Conversely to controls, in PE group there was a negative correlation between conjugation degree of $\mathrm{E}$ and GA $(R=-0.342$; $p=0.027)$ and a similar tendency in $\mathrm{GH}(R=-0.293 ; p$ $=0.051)$. In $\mathrm{CH}$ patients, we observed only the trend between conjugation of $\mathrm{F}$ and GA $(R=0.375 ; p=$ $0.059)$.

The stepwise multiple regression analyses were performed, similarly to those described in results section 3.2. The results reporting the associations between GC conjugation degree and particular disease (PE, GH or $\mathrm{CH})$ are presented in Table 3. The detailed results, also showing the influence of other cofactors, are presented in Supplementary Table 3.

\section{Discussion}

The disturbed GC balance was reported in many medical conditions, inter alia the polycystic ovary syndrome [32, 33], metabolic syndrome, insulin resistance [25], cholestasis [34] and mental disorders [27]. They are usually associated with the abnormal activity of $11 \beta$-HSD, $5 \alpha$ and/or $5 \beta$ reductase. Here we present that the disturbed metabolism of $\mathrm{F}$ is also manifested in women suffering from pregnancyrelated hypertension, including both $\mathrm{PE}$ and $\mathrm{GH}$.

Our preliminary study [12] surprisingly revealed that, despite the literature data proving the diminished expression and function of placental 11 $\beta$-HSD2 in PE [35-38], the apparent activity of renal $11 \beta$-HSD2 is significantly increased in that condition. This finding was in contradiction to other results. Heilmann et al. [11] reported higher $\mathrm{UFF} / \mathrm{UFE}$ ratio in the group comprising $\mathrm{GH}$ and $\mathrm{PE}$ patients indicating decreased function of $11 \beta$-HSD2. Walker et al. [10] presented no differences in UFF/UFE ratio between hypertensive pregnant women and controls. Our present study, conducted on a larger population and extended by the analysis of urinary metabolites of $\mathrm{F}$ and $\mathrm{E}$, entirely confirms our previous observations. Patients with PE presented significantly lower values of UFF/UFE than controls, and this difference remained significant after adjustment for confounders (Table 3). One need to emphasize that this paper presents the results obtained using HPLC-MS/MS method 
[23] instead of HPLC-FLD [12], and the mass spectrometry is known as the most specific and accurate way of detection. However, independently of the method applied, we observed the same dependencies in urinary $\mathrm{F}$ and $\mathrm{E}$. We suggest that the diminished function of placental $11 \beta$-HSD2 in PE, reported by others, might be a kind of compensatory mechanism limiting maternal $F$ levels that reach the fetus. The reduced UFF/UFE ratio could be attributed to the substantial proteinuria in $\mathrm{PE}$ patients as some authors reported increased function of renal $11 \beta$-HSD2 in nonpregnant proteinuric patients [39]. However, significantly lower UFF/UFE ratio also in usually non-proteinuric GH women suggests that other mechanisms should be considered to explain the enhanced $11 \beta$-HSD2 function in pregnancy-related hypertension. At the same time, $\mathrm{CH}$ group presented similar UFF/UFE ratios as controls, what confirms our previous conclusions [12] that the enhanced function of renal $11 \beta$-HSD2 concerns only women with pregnancy-related hypertension (PE and $\mathrm{GH}$ ).

We found that PE is associated with higher $\mathrm{THFs}_{\text {tot }}$ / THEs $_{\text {tot }}$ ratio (Table 2) what might indicate the increased function of $11 \beta$-HSD1 in that condition. On the one hand, the $\mathrm{THFs}_{\text {tot }} / \mathrm{THE}_{\text {tot }}$ is a non-specific parameter reflecting more precisely the overall balance between both $11 \beta$-HSD isoforms [9, 13, 39] than the actual function of $11 \beta$-HSD1. It is widely used in the clinical practice in the diagnosis of apparent mineralocorticoid excess, as lack or diminished function of 11 $\beta$-HSD2 implies much higher UFF/UFE ratio and also significantly increased THFs/THE [24, 40]. The literature data, however, show that in case of the proper function of $11 \beta$-HSD2 (reflected in normal value of UFF/UFE), the THFs/THE ratio describes quite acceptably the function of $11 \beta$-HSD1 [8, 28]. Our PE patients obtained not lower (as it could be supposed based on the lower UFF/UFE values) but higher $\mathrm{THFs}_{\text {tot }} / \mathrm{THEs}_{\text {tot }}$ ratio as compared to controls (0.346 vs. 0.280$)$. When analyzing not total but free metabolites of $\mathrm{F}$ and $\mathrm{E}\left(\mathrm{THF}_{\text {free }} / \mathrm{THE}_{\text {free }}\right.$ ratio), one will get similar conclusions to those derived from UFF/UFE, as PE was associated with lower $\mathrm{THF}_{\text {free }} /$ $\mathrm{THE}_{\text {free }}(\mathrm{R}=-0.214 ; p=0.034)$. Considering UFF/UFE, $\mathrm{THF}_{\text {free }} / \mathrm{THE}_{\text {free }}$ and $\mathrm{THFs}_{\text {tot }} / \mathrm{THEs}_{\text {tot }}$ we conclude that they reflect rather the augmented function of $11 \beta$-HSD2 than $11 \beta$-HSD1. The observed enhanced conjugation of $\mathrm{F}$ and THF in PE may further indicate the pursuit of woman's body to the efficient removal of active GC and its major metabolite.

All mentioned observations may lead to the conclusion that the $\mathrm{F}$ metabolism is significantly intensified in PE. Firstly, the similar $\mathrm{THFs}_{\text {tot }}+\mathrm{THEs}_{\text {tot }}$ indicates the comparable GC secretion (the equivalent activity of adrenal glands) in normotensive and preeclamptic pregnancy (380.1 vs. $394.2 \mu \mathrm{g} / \mathrm{mmol} \mathrm{Cr}$, respectively). However, plasma $\mathrm{F}$ concentration is markedly lower in PE (663 vs.
$782 \mathrm{nmol} / \mathrm{L}$ ), partially because of earlier GA at sampling, but also because of PE itself (Supplementary Table 3). Lower plasma $\mathrm{F}$ in PE suggests stronger GC metabolism in this group. The assumption of the enhanced $F$ clearance could be strengthened by lower UFF/UFE in PE (increased $11 \beta$-HSD2 function) and significantly higher $\mathrm{THF}_{\text {tot }} / \mathrm{F}_{\text {tot }}$ and alloTHF $\mathrm{tot}_{\text {tot }} / \mathrm{F}_{\text {tot }}$ (increased functions of $5 \beta$ - and $5 \alpha$-reductase, respectively) (Table 3 ). Lastly, the parameter indicating the metabolic clearance of $\mathrm{F}$ : $\left(\mathrm{THFs}_{\text {tot }}+\mathrm{THEs}_{\text {tot }}\right) / \mathrm{UFF}$ is almost two times higher in PE when compared to controls (141.59 vs. 76.95). Notably, lower plasma F in PE with comparable GC secretion (reflected in the amounts of tetrahydrometabolites in urine) may suggest the blunted HPA response in this condition. Lower $\mathrm{F}$ production in $\mathrm{PE}$ was previously reported by Ho et al. [5], who observed lower total and free F in maternal plasma in PE. They suggested it could result from the underactivity of maternal HPA axis.

Such conclusion about diminished HPA response cannot be derived from the results for $\mathrm{GH}$ group. Plasma $\mathrm{F}$ in $\mathrm{GH}$ patients was similar to the values obtained for normotensive women (Supplementary Table 1), in spite of evidently enhanced $\mathrm{F}$ metabolism. Intensified $\mathrm{F}$ metabolism is manifested in significantly lower UFF/UFE values (increased $11 \beta$-HSD2 function), higher $\mathrm{THF}_{\text {tot }} / \mathrm{F}_{\text {tot }}$ (increased $5 \beta$ reductase function) and almost two times higher $\left(\mathrm{THFs}_{\mathrm{tot}}+\right.$ THEs $_{\text {tot }}$ )/UFF (strongly enhanced F clearance). Moreover, the GC secretion is substantially increased. All these facts lead to the conclusion that the enhanced metabolism of $\mathrm{F}$ in $\mathrm{GH}$ patients is compensated by higher $\mathrm{F}$ secretion due to HPA activity (Table 2). Our observations do not corroborate with the results of Walker et al. [10] who showed no differences in 11 $\beta$-HSD function between PE, GH and normotensive pregnant women. Such discrepancies may result from relatively small study population in the cited study (13 controls, 7 women with GH and 8 with PE). Moreover, it is worth noting that we calculated $\mathrm{F}$ and $\mathrm{E}$ metabolites ratio considering not only THF and THE but also allotetrahydrometabolites.

The results obtained for patients with $\mathrm{CH}$ are very similar to those for normotensive women. However, worth noting is the fact that the balance in functions of $5 \alpha$ and $5 \beta$-reductases is shifted towards $5 \beta$-reductase (lower alloTHF tot $\mathrm{THF}_{\text {tot }}$ values in $\mathrm{CH}$, as presented in Tables 2 and 3). Surprisingly, this is in contradiction to results for nonpregnant hypertensive population presenting decreased activity of $5 \beta$-reductase [8].

We are aware of limitations of our study. During the study, in 2016, the diagnostic criteria of PE changed [41], and proteinuria is no longer obligatory for the diagnosis. We maintained the criteria with substantial proteinuria to ensure similar ones for all recruited patients, and for better comparability with previously published results. An important limitation is also the significantly earlier GA at 
sampling in PE group as compared to controls. Our study population comprised women who were admitted to hospital for routine tests or due to abnormalities arising during the course of pregnancy. Patients with PE, as a result of their rapidly deteriorating condition, were then usually enrolled to the hospital much earlier than other pregnant women. Secondly, the groups were poorly matched in regard to pre-pregnancy BMI. Moreover, women with PE were significantly more often nulliparous. The tendency to higher-pregnancy BMI among PE and GH patients, as well as the higher rates of nulliparity in PE but not in $\mathrm{GH}$, were previously reported and these features are mentioned among risk factors of pregnancy-specific hypertension [42]. Obesity and higher BMI are also linked to hypertension in general non-pregnant population [43]. As those confounders could adversely affect the results, the multiple regression analyses were performed to confirm our observations.

Strengths of our research are the relatively large group of patients as compared to other published studies [10] and thorough analysis of GC balance in pregnant women. We assessed the function of primary enzymes involved in $\mathrm{F}$ metabolism: $11 \beta$-HSD1, $11 \beta$-HSD2, $5 \alpha$ and $5 \beta$-reductase and the overall equilibrium between them. Additionally, the study group included both PE and GH patients, what brings the new insight into phenomena associated with pregnancyrelated hypertension.

Our main findings include: markedly intensified $\mathrm{F}$ metabolism manifested in the increased function of renal $11 \beta$-HSD2, $5 \alpha$ and $5 \beta$-reductase in PE as well as the enhanced function of renal $11 \beta$-HSD2 and $5 \beta$-reductase in $\mathrm{GH}$. The GC balance in PE is clearly shifted towards decreasing $\mathrm{F}$ concentration either due to the intensified conversion of $\mathrm{F}$ to $\mathrm{E}$ or enhanced production of tetrahydroand allo-tetrahydrometabolites. The observed changes are similar, however, less marked in GH. Importantly, we suggest the blunted response of HPA axis in PE, what was not found in other hypertensive disorders of pregnancy. Further studies concerning non-pregnant women with a history of PE and GH are needed to assess whether the observed changes in GC balance are limited to gestation, or they remain in the body of affected women after pregnancy. Moreover, the comprehensive prospective study, including women with high risk of $\mathrm{PE}$ and $\mathrm{GH}$, could bring the answer if any interference in GC balance during hypertensive pregnancy would be justified.

Funding This work was supported by the National Science Center (Narodowe Centrum Nauki) in Poland (grant number 2012/05/B/NZ7/ 02532).

\section{Compliance with ethical standards}

Conflict of interest The authors declare that they have no conflict of interest.
Open Access This article is distributed under the terms of the Creative Commons Attribution 4.0 International License (http://crea tivecommons.org/licenses/by/4.0/), which permits unrestricted use, distribution, and reproduction in any medium, provided you give appropriate credit to the original author(s) and the source, provide a link to the Creative Commons license, and indicate if changes were made.

\section{References}

1. B. Jim, S.A. Karumanchi, Preeclampsia: pathogenesis, prevention, and long-term complications. Semin. Nephrol. 37, 386-397 (2017)

2. T. Chaiworapongsa, P. Chaemsaithong, L. Yeo, R. Romero, Preeclampsia part 1: current understanding of its pathophysiology. Nat. Rev. Nephrol. 10, 466 (2014)

3. T. Hod, A.S. Cerdeira, S.A. Karumanchi, Molecular mechanisms of preeclampsia. Cold Spring Harb. Perspect. Med. 5, a023473 (2015)

4. G. Mastorakos, I. Ilias, Maternal and fetal hypothalamic-pituitaryadrenal axes during pregnancy and postpartum. Ann. N. Y. Acad. Sci. 997, 136-149 (2003)

5. J.T. Ho, J.G. Lewis, P. O'Loughlin, C.J. Bagley, R. Romero, G.A. Dekker, D.J. Torpy, Reduced maternal corticosteroid-binding globulin and cortisol levels in pre-eclampsia and gamete recipient pregnancies. Clin. Endocrinol. 66, 869-877 (2007)

6. K. Kosicka, A. Siemiątkowska, F. Główka, 11 $\beta$-Hydroxysteroid dehydrogenase 2 in preeclampsia. Int. J. Endocrinol. 2016, 5279462 (2016)

7. P. Konstantakou, G. Mastorakos, N. Vrachnis, J.W. Tomlinson, G. Valsamakis, Dysregulation of 11beta-hydroxysteroid dehydrogenases: implications during pregnancy and beyond. J. Matern. Fetal Neonatal Med. 30, 284-293 (2017)

8. C. Campino, C.A. Carvajal, J. Cornejo, B. San Martín, O. Olivieri, G. Guidi, G. Faccini, F. Pasini, J. Sateler, R. Baudrand, L. Mosso, G.I. Owen, A.M. Kalergis, O. Padilla, C.E. Fardella, 11 $\beta$ Hydroxysteroid dehydrogenase type-2 and type-1 (11ß-HSD2 and $11 \beta$-HSD1) and $5 \beta$-reductase activities in the pathogenia of essential hypertension. Endocrine 37, 106-114 (2010)

9. M.J.J. Finken, R.C. Andrews, R. Andrew, B.R. Walker, Cortisol metabolism in healthy young adults: sexual dimorphism in activities of A-ring reductases, but not $11 \beta$-hydroxysteroid dehydrogenases. J. Clin. Endocrinol. Metab. 84, 3316-3321 (1999)

10. B.R. Walker, P.M. Williamson, M.A. Brown, J.W. Honour, C.R. Edwards, J.A. Whitworth, 11 $\beta$-hydroxysteroid dehydrogenase and its inhibitors in hypertensive pregnancy. Hypertension 25, 626-630 (1995)

11. P. Heilmann, E. Buchheim, J. Wacker, R. Ziegler, Alteration of the activity of the $11 \beta$-hydroxysteroid dehydrogenase in pregnancy: relevance for the development of pregnancy-induced hypertension? J. Clin. Endocrinol. Metab. 86, 5222-5226 (2001)

12. K. Kosicka, A. Siemiątkowska, M. Krzyścin, G.H. Bręborowicz, M. Resztak, A. Majchrzak-Celińska, M. Chuchracki, F.K. Główka, Glucocorticoid metabolism in hypertensive disorders of pregnancy: analysis of plasma and urinary cortisol and cortisone. PloS ONE 10, e0144343 (2015)

13. L.I. Stirrat, J.R. O'Reilly, S.M. Barr, R. Andrew, S.C. Riley, A.F. Howie, M. Bowman, R. Smith, J.G. Lewis, F.C. Denison, S. Forbes, J.R. Seckl, B.R. Walker, J.E. Norman, R.M. Reynolds, Decreased maternal hypothalamic-pituitary-adrenal axis activity in very severely obese pregnancy: Associations with birthweight and gestation at delivery. Psychoneuroendocrinology 63, 135-143 (2016)

14. H.D. Mistry, N. Eisele, G. Escher, B. Dick, D. Surbek, C. Delles, G. Currie, D. Schlembach, M.G. Mohaupt, C. Gennari-Moser, Gestation-specific reference intervals for comprehensive spot urinary steroid hormone metabolite analysis in normal singleton 
pregnancy and 6 weeks postpartum. Reprod. Biol. Endocrinol. 13, $101-113$ (2015)

15. I. Bíró, A. Bufa, F. Wilhelm, Z. Mánfai, F. Kilár, P.M. Gocze, Urinary steroid profile in early pregnancy after in vitro fertilization: Urinary steroid profile after in vitro fertilization. Acta Obstet. Gynecol. Scand. 91, 625-629 (2012)

16. G.P.B. Kraan, H.J.G.M. Derks, N.M. Drayer, Quantification of polar glucocorticosteroids in the urine of pregnant and nonpregnant women: a comparison with $6 \alpha$-hydroxylated metabolites of cortisol in neonatal urine and amniotic fluid. J. Clin. Endocrinol. Metab. 51, 754-758 (1980)

17. M. Shimodaira, T. Nakayama, I. Sato, N. Sato, N. Izawa, Y. Mizutani, K. Furuya, T. Yamamoto, Glucocorticoid synthesisrelated genes: HSD11B1 and HSD11B2 in hypertensive disorders in pregnancy. Gynecol. Endocrinol. 29, 657-661 (2013)

18. L. Funghi, F. Damiani, C.-F. Yen, C.-L. Lee, A. Lombardi, F. Schatz, C.J. Lockwood, P. Marcolongo, F. Petraglia, F. Arcuri, Expression and regulation of $11 \beta$-hydroxysteroid dehydrogenase type 1 in first trimester human decidua cells: Implication in preeclampsia. Mol. Cell. Endocrinol. 437, 163-170 (2016)

19. World Health Organization: WHO recommendations for prevention and treatment of pre-eclampsia and eclampsia. (World Health Organization, Geneva, 2011)

20. American College of Obstetricians and Gynecologists; Task Force on Hypertension in Pregnancy, Hypertension in pregnancy. Report of the American College of Obstetricians and Gynecologists' Task Force on Hypertension in Pregnancy. Obstet. Gynecol. 122, 1122-1131 (2013)

21. J. Gadzinowski, M.D. Kaliszewska-Drozdowska, M. Kosińska, J. Mazela, B. Stoińska, Birth weight and gestational age of newborns from Wielkopolski and Lubuski regions. Ginekol. Pol. 74, 186-192 (2003)

22. M. Martineau, G. Papacleovoulou, S. Abu-Hayyeh, P.H. Dixon, H. Ji, R. Powrie, L. Larson, E.K. Chien, C. Williamson, Cholestatic pregnancy is associated with reduced placental 11ßHSD2 expression. Placenta 35, 37-43 (2014)

23. K. Kosicka, A. Siemiątkowska, D. Pałka, A. Szpera-Goździewicz, G.H. Bręborowicz, F.K. Główka, Detailed analysis of cortisol, cortisone and their tetrahydro- and allo-tetrahydrometabolites in human urine by LC-MS/MS. J. Pharm. Biomed. Anal. 140, 174-181 (2017)

24. M. Palermo, G. Delitala, F. Mantero, P.M. Stewart, C.H.L. Shackleton, Congenital deficiency of $11 \beta$-hydroxysteroid dehydrogenase (apparent mineralocorticoid excess syndrome): diagnostic value of urinary free cortisol and cortisone. J. Endocrinol. Invest. 24, 17-23 (2001)

25. R. Baudrand, C. Campino, C.A. Carvajal, O. Olivieri, G. Guidi, G. Faccini, J. Sateler, J. Cornejo, B.S. Martin, J.M. Dominguez, J. Cerda, L.M. Mosso, G.I. Owen, A.M. Kalergis, C.E. Fardella, Increased urinary glucocorticoid metabolites are associated with metabolic syndrome, hypoadiponectinemia, insulin resistance and $\beta$ cell dysfunction. Steroids 76, 1575-1581 (2011)

26. A. Mondok, I. Varga, E. Glaz, N. Szucs, M. Tóth, A. Patocs, G. Beko, K. Racz, 11ß-Hydroxysteroid dehydrogenase activity in acromegalic patients with normal or impaired carbohydrate metabolism. Steroids 74, 725-729 (2009)

27. N.E. Steen, P. Methlie, S. Lorentzen, I. Dieset, M. Aas, M. Nerhus, M. Haram, I. Agartz, I. Melle, J.P. Berg, O.A. Andreassen, Altered systemic cortisol metabolism in bipolar disorder and schizophrenia spectrum disorders. J. Psychiatr. Res. 52, 57-62 (2014)

28. G. Valsamakis, A. Anwar, J.W. Tomlinson, C.H.L. Shackleton, P. G. McTernan, R. Chetty, P.J. Wood, A.K. Banerjee, G. Holder, A. H. Barnett, P.M. Stewart, S. Kumar, 11 $\beta$-Hydroxysteroid dehydrogenase type 1 activity in lean and obese males with type 2 diabetes mellitus. J. Clin. Endocrinol. Metab. 89, 4755-4761 (2004)
29. R.J. Keizer, R.S. Jansen, H. Rosing, B. Thijssen, J.H. Beijnen, J. H.M. Schellens, A.D.R. Huitema, Incorporation of concentration data below the limit of quantification in population pharmacokinetic analyses. Pharmacol. Res. Perspect. 3, e00131 (2015)

30. D.C. Glass, C.N. Gray, Estimating mean exposures from censored data: exposure to benzene in the Australian petroleum industry. Ann. Occup. Hyg. 45, 275-282 (2001)

31. V. Tonetto-Fernandes, S.H.V. Lemos-Marini, H. Kuperman, L.M. Ribeiro-Neto, I.T.N. Verreschi, C.E. Kater, Serum 21-deoxycortisol, 17-hydroxyprogesterone, and 11-deoxycortisol in classic congenital adrenal hyperplasia: clinical and hormonal correlations and identification of patients with $11 \beta$-hydroxylase deficiency among a large group with alleged 21-hydroxylase deficiency. J. Clin. Endocrinol. Metab. 91, 2179-2184 (2006)

32. Z. Blumenfeld, G. Kaidar, N. Zuckerman-Levin, E. Dumin, C. Knopf, Z. Hochberg, Cortisol-metabolizing enzymes in polycystic ovary syndrome. Clin. Med. Insights Reprod. Health 10, 9-13 (2016)

33. D.A. Vassiliadi, T.M. Barber, B.A. Hughes, M.I. McCarthy, J.A. H. Wass, S. Franks, P. Nightingale, J.W. Tomlinson, W. Arlt, P. M. Stewart, Increased $5 \alpha$-reductase activity and adrenocortical drive in women with polycystic ovary syndrome. J. Clin. Endocrinol. Metab. 94, 3558-3566 (2009)

34. C. Quattropani, B. Vogt, A. Odermatt, B. Dick, B.M. Frey, F.J. Frey, Reduced activity of $11 \beta$-hydroxysteroid dehydrogenase in patients with cholestasis. J. Clin. Invest. 108, 1299-1305 (2001)

35. W. Hu, H. Wang, H. Huang, Analysis of gene expression and preliminary study of methylation about $11 \beta$-HSD2 gene in placentas of Chinese pre-eclampsia patients of Han ethnicity. J. Obstet. Gynaecol. Res. 41, 343-349 (2015)

36. E. Schoof, M. Girstl, W. Frobenius, M. Kirschbaum, H.G. Dörr, W. Rascher, J. Dötsch, Decreased gene expression of $11 \beta$ hydroxysteroid dehydrogenase type 2 and 15hydroxyprostaglandin dehydrogenase in human placenta of patients with preeclampsia. J. Clin. Endocrinol. Metab. 86, 1313-1317 (2001)

37. C.O. McCalla, V.L. Nacharaju, O. Muneyyirci-Delale, S. Glasgow, J.G. Feldman, Placental 11 $\beta$-hydroxysteroid dehydrogenase activity in normotensive and pre-eclamptic pregnancies. Steroids 63, 511-515 (1998)

38. M. Aufdenblatten, M. Baumann, L. Raio, B. Dick, B.M. Frey, H. Schneider, D. Surbek, B. Hocher, M.G. Mohaupt, Prematurity is related to high placental cortisol in preeclampsia. Pediatr. Res. 65, 198-202 (2009)

39. M.N. Kerstens, H. Buter, G.J. Navis, R.P.F. Dullaart, 11 $\beta$ Hydroxysteroid dehydrogenase activity in proteinuric patients and the effect of angiotensin-II receptor blockade. Eur. J. Clin. Invest. 32, 513-518 (2002)

40. M. Yau, H.S.A. Azkawi, S. Haider, A. Khattab, M.A. Badi, W. Abdullah, A.A. Senani, R.C. Wilson, T. Yuen, M. Zaidi, M.I. New, A novel mutation in HSD11B2 causes apparent mineralocorticoid excess in an Omani kindred. Ann. N. Y. Acad. Sci. 1376, 65-71 (2016)

41. B.W.J. Mol, C.T. Roberts, S. Thangaratinam, L.A. Magee, C.J.M. de Groot, G.J. Hofmeyr, Pre-eclampsia. Lancet 387, 999-1011 (2016)

42. J. Villar, G. Carroli, D. Wojdyla, E. Abalos, D. Giordano, H. Ba'aqeel, U. Farnot, P. Bergsjø, L. Bakketeig, P. Lumbiganon, L. Campodónico, Y. Al-Mazrou, M. Lindheimer, M. Kramer; World Health Organization Antenatal Care Trial Research Group, Preeclampsia, gestational hypertension and intrauterine growth restriction, related or independent conditions? Am. J. Obstet. Gynecol. 194, 921-931 (2006)

43. M.E. Hall, J.M. do Carmo, A.A. da Silva, L.A. Juncos, Z. Wang, J.E. Hall, Obesity, hypertension, and chronic kidney disease. Int. J. Nephrol. Renov. Dis. 7, 75-88 (2014) 